\title{
Effects of intravenous exenatide in type 2 diabetic patients with congestive heart failure: a double-blind, randomised controlled clinical trial of efficacy and safety
}

\author{
D. Nathanson • B. Ullman • U. Löfström • A. Hedman • \\ M. Frick • Å. Sjöholm • T. Nyström
}

Received: 2 December 2011 / Accepted: 12 December 2011 /Published online: 13 January 2012

(C) Springer-Verlag 2012

\begin{abstract}
Aims/hypothesis The aim of this study was to determine whether exenatide improves haemodynamic function in patients with type 2 diabetes with congestive heart failure (CHF).

Methods The main eligibility criteria for inclusion were: male/female (18-80 years) with type 2 diabetes and CHF (ejection fraction $\leq 35 \%$, and New York Heart Association functional class III or IV). Out of 237 patients screened, 20 male type 2 diabetic patients participated in this crossover trial design and were allocated (sequentially numbered) to $i$. v. infusions during two consecutive days with (1) exenatide $(0.12 \mathrm{pmol} / \mathrm{kg} / \mathrm{min})$; and (2) placebo for $6 \mathrm{~h}$ followed by a washout period for $18 \mathrm{~h}$, at Stockholm South Hospital, Sweden. Patients and researchers were blinded to the assignment. Cardiac haemodynamic variables were determined by right heart catheterisation. The primary endpoint was defined as an increase in cardiac index (CI) or a decrease in pulmonary capillary wedge pressure (PCWP) of $\geq 20 \%$. Secondary endpoints were tolerability and safety of exenatide infusion. Results CI increased at 3 and $6 \mathrm{~h}$ by $0.4 \pm 0.1(23 \%)$ and $0.33 \pm 0.1(17 \%) 1 \mathrm{~min}^{-1} \mathrm{~m}^{-2}$, during exenatide infusion vs $-0.02 \pm 0.1(-1 \%)$ and $-0.08 \pm 0.1(-5 \%) 1 \mathrm{~min}^{-1} \mathrm{~m}^{-2}$ during placebo $(p=0.003)$; and heart rate (HR) increased at 1,3 and $6 \mathrm{~h}$ by $8 \pm 3(11 \%), 15 \pm 4(21 \%)$ and $21 \pm 5(29 \%)$ beats per
\end{abstract}

\footnotetext{
D. Nathanson · Å. Sjöholm • T. Nyström $(\bowtie)$

Division of Internal Medicine, Department of Clinical

Science and Education, Karolinska Institutet,

Södersjukhuset AB,

SE-118 83 Stockholm, Sweden

e-mail: thomas.nystrom@sodersjukhuset.se

B. Ullman · U. Löfström • A. Hedman · M. Frick

Division of Cardiology, Department of Clinical

Science and Education, Karolinska Institutet,

Stockholm, Sweden
}

min (bpm), during exenatide infusion vs $-1 \pm 2(-2 \%), 1 \pm 1$ $(2 \%)$ and $6 \pm 2(8 \%) \mathrm{bpm}$, during placebo $(p=0.006)$; and PCWP decreased at 1,3 and $6 \mathrm{~h}$ by $-1.3 \pm 0.8(-8 \%),-1.2 \pm$ $1(-8 \%)$ and $-2.2 \pm 0.9(-15 \%) \mathrm{mmHg}$, during exenatide infusion vs $0.3 \pm 0.5(2 \%), 1 \pm 0.6(6 \%)$ and $1.4 \pm 0.7(8 \%)$ $\mathrm{mmHg}$, during placebo $(p=0.001)$. No serious adverse event was observed. Adverse events were reported in nine patients (six, nausea; two, increased HR; one, increased systolic blood pressure).

Conclusions/interpretation Infusion of exenatide in male type 2 diabetic patients with CHF increased the $\mathrm{CI}$ as a result of chronotropy, with concomitant favourable effects on PCWP and reasonable tolerability of the drug. The clinical implications of using exenatide in patients with CHF are still not clear and further studies are warranted.

Trial registration: www.isrctn.org/ISRCTN47533126

Funding: This study was funded through the regional agreement on medical training and clinical research (ALF) between Stockholm County Council and the Karolinska Institute, by the Swedish Society for Medical Research, the Swedish Society of Medicine, Stiftelsen Serafimerlasarettet, the Swedish Heart and Lung foundation, Eli Lilly Amylin Alliance, the European Foundation for the Study of Diabetes, Karolinska Institutet Foundations, and Stiftelsen Olle Engkvist Byggmästare.

Keywords Congestive heart failure $\cdot$ Double-blind randomised trial · Exenatide - GLP-1 · Heart catheterisation . Type 2 diabetes

$\begin{array}{ll}\text { Abbreviations } \\ \text { AF } & \text { Atrial fibrillation } \\ \text { CABG } & \text { Coronary artery bypass graft } \\ \text { CAD } & \text { Coronary artery disease }\end{array}$




$\begin{array}{ll}\text { CHF } & \text { Congestive heart failure } \\ \text { CI } & \text { Cardiac index } \\ \text { CO } & \text { Cardiac output } \\ \text { CVD } & \text { Cardiovascular disease } \\ \text { DPP-4 } & \text { Dipeptidyl peptidase-4 } \\ \text { eGFR } & \text { Estimated GFR } \\ \text { GLP-1 } & \text { Glucagon-like peptide-1 } \\ \text { HR } & \text { Heart rate } \\ \text { LV } & \text { Left ventricular } \\ \text { MAP } & \text { Mean arterial blood pressure } \\ \text { MI } & \text { Myocardial infarction } \\ \text { NYHA } & \text { New York Heart Association classification } \\ \text { PADP } & \text { Pulmonary arterial diastolic pressure } \\ \text { PAP } & \text { Pulmonary artery pressure } \\ \text { PASP } & \text { Pulmonary arterial systolic pressure } \\ \text { PCWP } & \text { Pulmonary capillary wedge pressure } \\ \text { PVR } & \text { Pulmonary vascular resistance } \\ \text { RAP } & \text { Right atrial pressure } \\ \text { SV } & \text { Stroke volume } \\ \text { SVR } & \text { Systemic vascular resistance }\end{array}$

\section{Introduction}

There is a growing body of evidence that the intestinally produced peptide hormone, glucagon-like peptide-1 (GLP-1), might have a beneficial role in cardiovascular function in addition to its antihyperglycaemic action [1]. It was recently shown that GLP-1 improves left ventricular (LV) haemodynamics in a canine model with advanced dilated cardiomyopathy [2]. The observation that these effects were accompanied by an increase in myocardial uptake of glucose, without any change in levels of insulin, suggests that GLP-1 exerts insulinomimetic effects in the myocardium [2]. Furthermore, some human studies demonstrate beneficial effects of GLP-1 on the heart. Short term infusion of GLP-1 in patients with acute myocardial infarction (MI) improves LV systolic function following successful reperfusion [3], as does chronic infusion in patients with congestive heart failure (CHF) [4]. However, not all studies have arrived at the same conclusion [5].

To date, studies evaluating cardiac filling pressure evoked by GLP-1 treatment in humans by the gold standard method (heart catheterisation) are sparse. GLP-1 infusion before and after coronary artery bypass graft (CABG) was found to reduce the need for inotropic agents to achieve optimal haemodynamic results [6], and short term infusion of GLP-1 protects the heart against ischaemic LV dysfunction after balloon occlusion within the coronary artery in humans [7]. GLP-1 is rapidly degraded by the enzyme dipeptidyl peptidase-4 (DPP-4) to the split product GLP-1 (9-36), which does not interact with the GLP-1 receptor [8]. Because of the rapid degradation of GLP-1, different GLP-1 receptor agonists, for example exenatide and liraglutide, which are resistant to DPP-4, have been developed and are currently approved for the treatment of type 2 diabetes. These agonists exert their effects via the GLP-1 receptor and mimic the actions evoked by native GLP-1 [1]. Chronic treatment with exenatide in mice with dilated cardiomyopathy [9] and rats with CHF [10] delays the progression of heart failure and prolongs the animals' survival, probably as a result of changes in glucose metabolism. Whether exenatide can directly improve cardiac output (CO) remains elusive and has not been studied in humans.

The aims of the present study were to investigate whether exenatide improves haemodynamic function in type 2 diabetic patients with CHF independent of glycaemia, and the safety/tolerability of this drug, in an acute setting.

\section{Methods}

Participants Patients were recruited from Stockholm South Hospital, Sweden. Inclusion criteria were: male and female participants, 18-80 years of age, known type 2 diabetes, hospitalisation owing to CHF according to the New York Heart Association classification (NYHA) III-IV, LV systolic dysfunction with a documented LV ejection fraction of $\leq 35 \%$ (assessed by echocardiography), and a clinically stable period of $24 \mathrm{~h}$ using established therapy (diuretics, ACE/A-II inhibitors and $\beta$-blockers). Exclusion criteria were: type 1 diabetes, ongoing treatment with inotropic agents, acute coronary syndrome or documented acute MI within the previous 8 weeks, active myocarditis, significant aortic stenosis or mitral/tricuspid regurgitation, symptomatic primary pulmonary disease, ventricular arrhythmias, second- or third-degree atrioventricular block, implanted cardioverter defibrillator or biventricular pacemaker, supine systolic blood pressure $<85$ or $>200 \mathrm{mmHg}$, primary renal or hepatic impairment (estimated GFR [eGFR] $<30 \mathrm{ml} / \mathrm{min}$, aspartate aminotransferase/alanine aminotransferase $>2$ times upper limit of normal), hypokalaemia $(<3.5 \mathrm{mmol} / \mathrm{l})$ or hyperkalaemia $(>5.5 \mathrm{mmol} / \mathrm{l})$, significant anaemia $(\mathrm{Hb}<100 \mathrm{~g} / \mathrm{l})$, pregnancy, or present or previous treatment with a GLP-1 receptor agonist or a DPP-4 inhibitor. Participants were screened for diabetic retinopathy by mydriatic fundal retinal photography. The protocol was approved by the Swedish Central Ethical Review Board and the Medical Products Agency and conducted according to the principles of the Declaration of Helsinki 1975. Written informed consent was obtained from all participants.

Study design This was a single-centre, randomised, twoperiod crossover, double-blind study. The primary endpoint was defined as an increase in cardiac index $(\mathrm{CI})$ or a decrease in pulmonary capillary wedge pressure (PCWP) of $\geq 20 \%$. Secondary endpoints were changes in mean arterial blood 
pressure (MAP) and mean pulmonary arterial pressure (PAP), and tolerability of exenatide in this acute setting. Potential adverse events were monitored continuously and reported annually to the Medical Products Agency. The criterion to break the blinding and stop the study was deterioration of heart function in more than three patients or one serious adverse event.

The study protocol was performed in two sessions over two consecutive days. After an overnight fast, all participants underwent i.v. infusion with glucose $(50 \mathrm{mg} / \mathrm{ml} ; 50 \mathrm{ml} / \mathrm{h})$ and insulin (Actrapid, Novo Nordisk, Bagsværd, Denmark, 1-6 U/h to maintain normoglycaemia [4-6 mmol/1]), and exenatide $\left(0.12 \mathrm{pmol} \mathrm{kg}^{-1} \mathrm{~min}^{-1}\right)$ or placebo (solvent used in the exenatide infusion) provided by Eli Lilly Amylin Alliance (Indianapolis, IN, USA) in a syringe pump device (IVAC, Medical Systems, Basingstoke, UK) for $6 \mathrm{~h}$, followed by a washout period for $18 \mathrm{~h}$. The dose of exenatide was estimated from an earlier human study [11] avoiding plasma levels of exenatide exceeding $3 \mathrm{nmol} / \mathrm{l}$, as suggested by earlier experimental data [12]. In the two session blockrandomisation procedure, group A received exenatide during day 1 followed by placebo on day 2 and group B received placebo on day 1 followed by exenatide on day 2 (Fig. 1). Participants were given their regular medication in the morning (07:00 hours) and in the evening (19:00 hours), except for prandial insulin, metformin and sulfonylurea, which were withheld during the study protocol. NPH insulin was given at bed time (22:00-23:00 hours). Participants were confined to the intensive care unit during the whole study period, including $6 \mathrm{~h}$ in a supine position during measurements. The main haemodynamic measurements (heart rate [HR], right atrial pressure [RAP], PAP, PCWP, MAP, CO, CI, stroke volume [SV], pulmonary vascular resistance [PVR], and systemic vascular resistance [SVR]) were recorded at baseline (before the start of the infusions) and thereafter at 1, 3 and $6 \mathrm{~h}$ after the start of infusion. All patients remained fasted during the study protocol.

Concomitant medications Details of all medications used by the patients studied are given in Table 1. All patients were on stable doses of angiotensin-converting enzyme or angiotensin-II receptor antagonists, $\beta$-blockers (except one patient) and diuretics. All patients but three received pharmacological glucose-lowering therapy.

Thermodilution The thermodilution catheters were inserted via the internal jugular veins. The tip of the catheter was advanced into the pulmonary artery to reach a position adequate for monitoring of the wedge pressure. Pulmonary artery thermodilution catheters (7.5 F; AH-05050, Arrow International, Bernville, PA, USA) and the Siemens Sirecust SC 9000XL computer (Siemens, Denver, CO, USA) were used to calculate $\mathrm{CO}$ from the modified Steward-Hamilton equation. The injections were made by hand, $10 \mathrm{ml}$ of ice-
Fig. 1 Design of the doubleblind randomised crossover clinical trial. Patients were allocated in a two-period crossover double-blind manner receiving a $6 \mathrm{~h}$ infusion protocol followed by a washout period for $18 \mathrm{~h}$. Group A received exenatide during day 1 followed by re-allocation to placebo on day 2. Group B received placebo on day 1 followed by re-allocation to exenatide on day 2, i.e. patients were their own controls

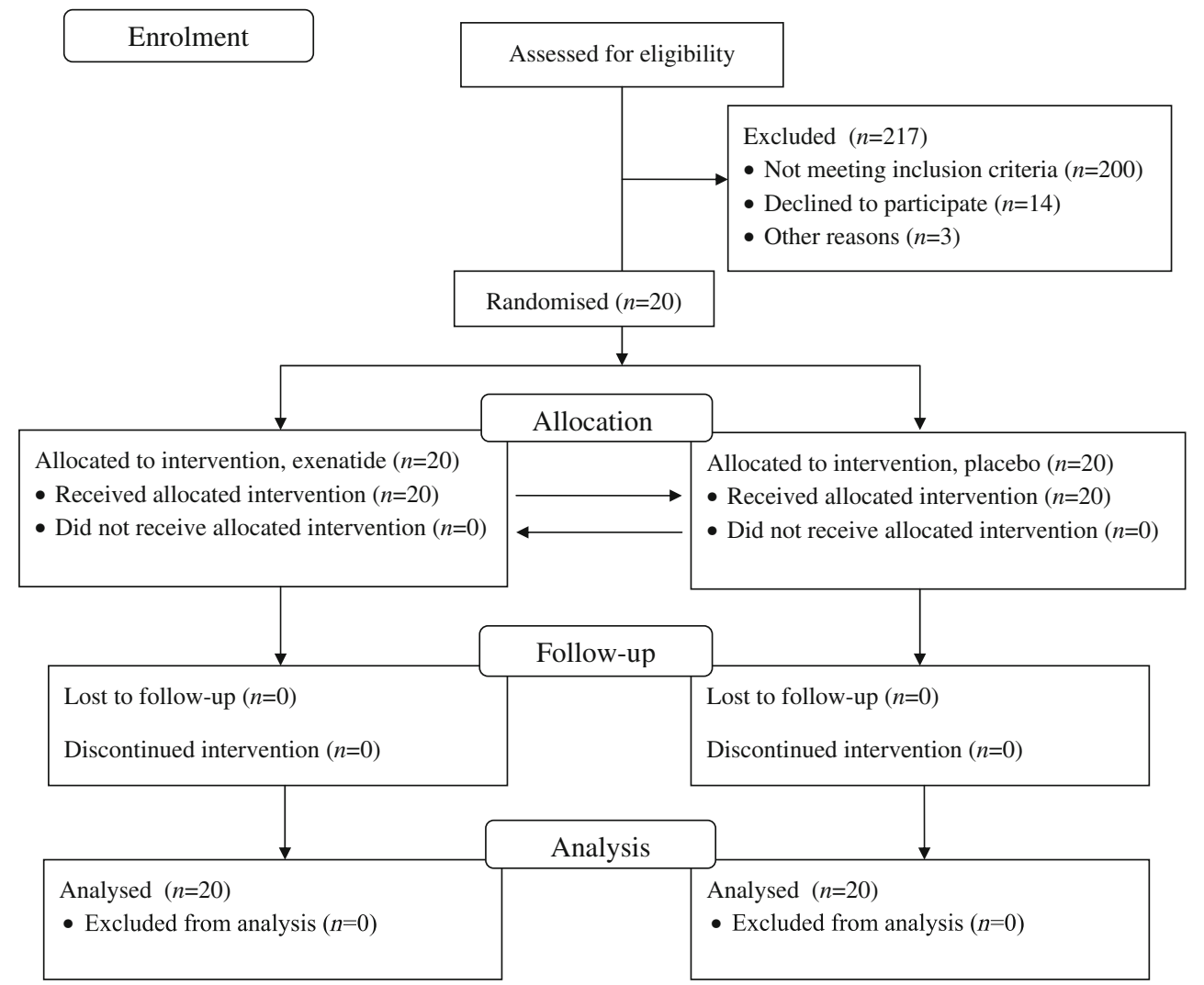


Table 1 Participants' characteristics

\begin{tabular}{|c|c|}
\hline Variable & Value \\
\hline Patients $(n)$ & 20 \\
\hline Male/female & $20 / 0$ \\
\hline Age (years) & $66 \pm 1$ \\
\hline BMI $\left(\mathrm{kg} / \mathrm{m}^{2}\right)$ & $31 \pm 1$ \\
\hline Diabetes duration (years) & $13 \pm 2$ \\
\hline Microalbuminuria (20-200 $\mu \mathrm{g} / \mathrm{min})$ & $7 / 20$ \\
\hline Mean $(\mu \mathrm{g} / \mathrm{min})$ & $36 \pm 18$ \\
\hline Macroalbuminuria ( $>200 \mu \mathrm{g} / \mathrm{min})$ & $5 / 20$ \\
\hline Mean $(\mu \mathrm{g} / \mathrm{min})$ & $368 \pm 63$ \\
\hline Diabetic retinopathy & $16 / 20$ \\
\hline None & 4 \\
\hline Mild non-proliferative & 7 \\
\hline Moderate non-proliferative & 7 \\
\hline Severe non-proliferative & 2 \\
\hline $\mathrm{HbA}_{1 \mathrm{c}}(\%)$ & $8.1 \pm 0.4$ \\
\hline $\mathrm{HbA}_{1 \mathrm{c}}(\mathrm{mmol} / \mathrm{mol})$ & $65 \pm 4$ \\
\hline Cholesterol (mmol/l) & $4.1 \pm 0.3$ \\
\hline HDL-cholesterol (mmol/l) & $1.0 \pm 0.1$ \\
\hline LDL-cholesterol (mmol/1) & $2.4 \pm 0.2$ \\
\hline Triacylglycerol (mmol/l) & $1.4 \pm 0.1$ \\
\hline 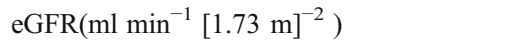 & $64 \pm 7$ \\
\hline \multicolumn{2}{|l|}{ NYHA functional class (\%) } \\
\hline III & 55 \\
\hline IV & 45 \\
\hline LV ejection fraction $(\%)$ & $26 \pm 2$ \\
\hline \multicolumn{2}{|l|}{ Risk factors for heart failure (\%) } \\
\hline CAD & 60 \\
\hline Hypertension & 80 \\
\hline DCM & 10 \\
\hline \multicolumn{2}{|l|}{ Smoking (\%) } \\
\hline Former smoker & 60 \\
\hline Current smoker & 40 \\
\hline $\mathrm{AF}(\%)$ & 55 \\
\hline \multicolumn{2}{|l|}{ Concomitant medication (\%) } \\
\hline ACE inhibitors/A-II receptor antagonists & 100 \\
\hline$\beta$-Blocker & 95 \\
\hline Loop diuretic & 100 \\
\hline Spironolactone & 40 \\
\hline ASA/clopidogrel & 55 \\
\hline Warfarin & 55 \\
\hline \multicolumn{2}{|l|}{ Diabetes treatment $(\%)$} \\
\hline Insulin & 60 \\
\hline Metformin & 25 \\
\hline Sulfonylurea & 5 \\
\hline Combination therapy & 5 \\
\hline Diet only & 15 \\
\hline
\end{tabular}

Values are means \pm SEM

A-II receptor antagonists, angiotensin-II receptor antagonists; DCM, dilated cardiomyopathy chilled $\left(10^{\circ} \mathrm{C}\right)$ glucose $(50 \mathrm{mg} / \mathrm{ml})$, and always completed within $3 \mathrm{~s}$. The mean of five consecutive $\mathrm{CO}$ measurements were used in all time points.

Invasive arterial blood pressure and heart rate measurements A catheter with an arterial line primed with $\mathrm{NaCl}$ $(0.9 \%)$ was positioned in the radial artery in the right wrist of all patients. Calculation of HR was based on the average $\mathrm{R}-\mathrm{R}$ interval over the final $10 \mathrm{~s}$ (Siemens Sirecust SC 9000XL).

Biochemical analyses Serum insulin and C-peptide levels were measured by an immunometric method with monoclonal antibodies (Modular E 170, Roche Diagnostics Scandinavia, Stockholm, Sweden). NEFA levels were determined using a NEFA-HR kit (Wako Chemicals, Neuss, Germany) on a Thermo T20xti instrument (Kone, Espoo, Finland). Plasma glucagon concentrations were measured using a glucagon radioimmunoassay kit (Euria-Glucagon, EuroDiagnostica, Dieren, the Netherlands) in a multigamma counter. Plasma lactate levels were measured using an ABL800 FLEX blood gas analyser (Labcompare, San Francisco, CA, USA). Plasma exenatide levels were measured by ELISA (Tandem Labs, San Diego, CA, USA). Other routine laboratory variables were measured by the local clinical chemistry laboratory (Stockholm South Hospital).

Statistical analyses All analyses were defined in the statistical analysis plan, before un-blinding. A cardiologist, blinded to the allocated treatment, scrutinised all haemodynamic data (from every time point) from print-outs from the Sirecust monitor to certify that all data were correctly reported in the data file. Values are presented as means \pm SEM or $n$ for categorical variables. A general linear mixed model with participant and time as repeated factors and treatment as a fixed factor was used to test the effect of treatment on continuous variables. The baseline value for the outcome variables was included in the model (unstructured covariance matrix) as covariates. This model assumes that pair-wise correlations are not constrained by the data, that is, no assumptions are made about the relative magnitude of the correlation between any of the pairs of observations. If an overall significant difference between exenatide vs placebo was present, pair-wise comparisons with Tukey's least significant difference test were performed to determine differences between active treatment and placebo at each time point. McNemar's and sign tests were used for dichotomous variables, i.e. proportions. Paired $t$ tests were used to compare the infused amount of insulin between exenatide and placebo infusions. To detect any potential carry-over effects, tests for the interaction of treatment and period (treatment $\times$ period) were performed, separate figures for each variable for Group A vs Group B were compared and 
finally, paired $t$ tests between haemodynamic baseline levels for days 1 and 2 in Group A were performed. All variables for primary and secondary endpoints were normally distributed as tested by Shapiro-Wilk's test.

Power calculation The calculation was carried out according to previous studies $[3,13]$. The primary endpoint was defined as a clinically meaningful improvement, i.e. a relative increase in CI of $\geq 20 \%$. This was assumed by an absolute change of CI from 2.0 to $2.41 \mathrm{~min}^{-1} \mathrm{~m}^{-2}$ with an $\mathrm{SD}$ of $1.01 \mathrm{~min}^{-1} \mathrm{~m}^{-2}$, between exenatide and placebo treatment. With an $\alpha$ error of 0.05 , two sided testing, and a power of 0.80 , we needed 17 patients in the study. However, as dropouts were estimated to be $\sim 20 \%$, we estimated at least 20 patients would be required to show differences in the primary endpoint between treatments.

\section{Results}

Baseline characteristics Baseline characteristics of the study population are shown in Table 1. Despite considerable efforts to include both female and male study participants, the majority of patients screened for the study were male; only three women matched the criteria and all declined to participate (Fig. 1). Baseline haemodynamic variables were consistent with CHF with a depression of CI and an elevation of PCWP (Table 2). We found no significant carry-over effects in any of the primary endpoint variables.

Haemodynamic effects There were no missing data in the primary endpoint variables. The exenatide infusion rate was $0.12 \mathrm{pmol} \mathrm{kg}^{-1} \min ^{-1}$ during the $6 \mathrm{~h}$ of infusion for all patients, except for a dose reduction of $8 \%$ over $3 \mathrm{~h}$ in one patient, due to nausea. All haemodynamic data are given in Table 2. Relative changes of the primary endpoints CI and PCWP from baseline and during the protocol are given in Fig. $2 \mathrm{a}$ and $\mathrm{b}$. The proportion of participants, during exenatide vs placebo infusions, that reached the endpoints by an increase of $20 \%$ in CI were; at $1 \mathrm{~h} 5 / 20$ vs $3 / 20(p=0.7)$, at $3 \mathrm{~h} 13 / 20$ vs $2 / 20$ ( $p=0.003$ ), and at 6 h $12 / 20$ vs $3 / 20$ ( $p=$ $0.004)$, and at any time point during the protocol, $15 / 20 \mathrm{vs}$ $4 / 20$ ( $p=0.001)$; and by a decrease of $20 \%$ in PCWP were; at $1 \mathrm{~h} 6 / 20$ vs $2 / 20(p=0.2)$, at $3 \mathrm{~h} 6 / 20$ vs $0 / 20(p=0.03)$ and at $6 \mathrm{~h} 10 / 20 \mathrm{vs} 1 / 20(p=0.004)$, and at any time point during the protocol, $10 / 20$ vs $2 / 20(p=0.008)$. CI increased significantly from baseline during exenatide vs placebo infusion at $3 \mathrm{~h}$, by $0.4 \pm 0.1 \mathrm{vs}-0.02 \pm 0.011 \mathrm{~min}^{-1} \mathrm{~m}^{-2}(21 \%$ vs $-1 \%)$; and at $6 \mathrm{~h}$ by $0.33 \pm 0.1 \mathrm{vs}-0.08 \pm 0.11 \mathrm{~min}^{-1} \mathrm{~m}^{-2}(18 \%$ vs $-5 \%$ ). HR increased significantly from baseline during exenatide vs placebo infusion at $1 \mathrm{~h}$ by $8 \pm 3$ vs $-1 \pm 2 \mathrm{bpm}$ $(11 \%$ vs $-2 \%), 3$ h $15 \pm 4$ vs $1 \pm 0.6 \mathrm{bpm}(21 \%$ vs $2 \%)$ and at 6 h $21 \pm 5$ vs $6 \pm 2$ bpm ( $29 \%$ vs $8 \%$ ). SV did not change significantly over time during exenatide vs placebo infusion. PCWP decreased significantly from baseline during exenatide vs placebo infusion at $1 \mathrm{~h}-1.3 \pm 0.8$ vs $0.3 \pm 0.5 \mathrm{mmHg}(-8 \%$ vs $2 \%)$, at $3 \mathrm{~h}-1.2 \pm 1$ vs $1 \pm 0.6 \mathrm{mmHg}(-8 \%$ vs $6 \%)$ and at $6 \mathrm{~h}-2.2 \pm 0.9$ vs $1.4 \pm 0.7 \mathrm{mmHg}(-15 \%$ vs $8 \%$ ). The decrease in PCWP remained significant ( $p=0.02$, overall) after adjustment for HR. RAP slightly decreased from baseline during exenatide vs placebo infusion at $3 \mathrm{~h}$ by $-1.4 \pm 0.7$ vs $0.3 \pm$ $0.7 \mathrm{mmHg}(-17 \%$ vs $3.4 \%)$. Neither MAP nor PAP differed between exenatide and placebo infusions. Furthermore, there were no overall significant differences between the effects of exenatide vs placebo on PVR. However, a slight (albeit statistically significant) decrease in SVR during exenatide vs placebo infusion was observed at $3 \mathrm{~h}-160 \pm 79$ vs $70 \pm 49$ dyne $\mathrm{s}^{-1} \mathrm{~cm}^{-5}\left[1\right.$ dyne $\left.=10^{-5} \mathrm{~N}\right](-9 \%$ vs $4 \%)$, although not over time. Fifty-five per cent and $60 \%$ of the study participants suffered from atrial fibrillation (AF) and coronary artery disease (CAD), respectively. No interaction was observed between $\mathrm{AF}$ or non-AF patients on treatment-induced changes in HR $(p=0.3), \mathrm{CI}(p=0.9)$ and PCWP $(p=0.2)$. However, an interaction was observed between participants with and without CAD on exenatide treatment for changes in $\mathrm{CI}(p=0.009)$, but not for HR $(p=0.3)$ or PCWP $(p=0.7)$. This interaction was reflected by a slight increase in changes in CI for each time point; baseline ( $1.8 \pm 0.1$ vs $\left.1.9 \pm 0.21 \mathrm{~min}^{-1} \mathrm{~m}^{-2}\right)$, $0 \mathrm{~h}\left(1.8 \pm 0.1\right.$ vs $\left.1.8 \pm 0.21 \mathrm{~min}^{-1} \mathrm{~m}^{-2}\right), 1 \mathrm{~h}(2.1 \pm 0.1$ vs $2.0 \pm$ $\left.0.21 \mathrm{~min}^{-1} \mathrm{~m}^{-2}\right), 3 \mathrm{~h}\left(2.4 \pm 0.1\right.$ vs $\left.1.9 \pm 0.11 \mathrm{~min}^{-1} \mathrm{~m}^{-2}\right)$ and $6 \mathrm{~h}$ $\left(2.3 \pm 0.1\right.$ vs $\left.2.0 \pm 0.21 \mathrm{~min}^{-1} \mathrm{~m}^{-2}\right)$ in participants with CAD vs non-CAD.

Metabolic effects All metabolic data are given in Table 2. Normoglycaemia was achieved by adjustments of insulin infusion rate during exenatide and placebo infusions. Participants required somewhat less exogenous insulin during exenatide vs placebo infusion ( 9 vs $13 \mathrm{U} /$ patient, $p=0.002$ ). There were no significant differences in glucagon, insulin or lactate levels between exenatide and placebo infusions. C-peptide levels increased significantly during exenatide infusion vs placebo infusion at 1, 3 and $6 \mathrm{~h}$. Serum concentrations of NEFAs increased significantly during exenatide and placebo infusions at $6 \mathrm{~h}$ compared with baseline, and were higher at $6 \mathrm{~h}$ after exenatide vs placebo infusions.

Adverse events No serious adverse event was observed. Adverse events were reported in $45 \%$ of the exenatide infusions and $0 \%$ of the placebo infusions. Six patients suffered adverse events in the form of nausea/vomiting, but three patients experienced cardiovascular adverse events: two patients with $\mathrm{AF}$ experienced an increase in heart rate to an extent (from 83 to $161 \mathrm{bpm}$ and 116 to $124 \mathrm{bpm}$, respectively) that necessitated the use of digoxin $(0.25 \mathrm{mg}$ i.v.) during (at $3 \mathrm{~h}$ ) and directly after (at $6 \mathrm{~h}$ ) the exenatide infusion; one patient had an increase in systolic 


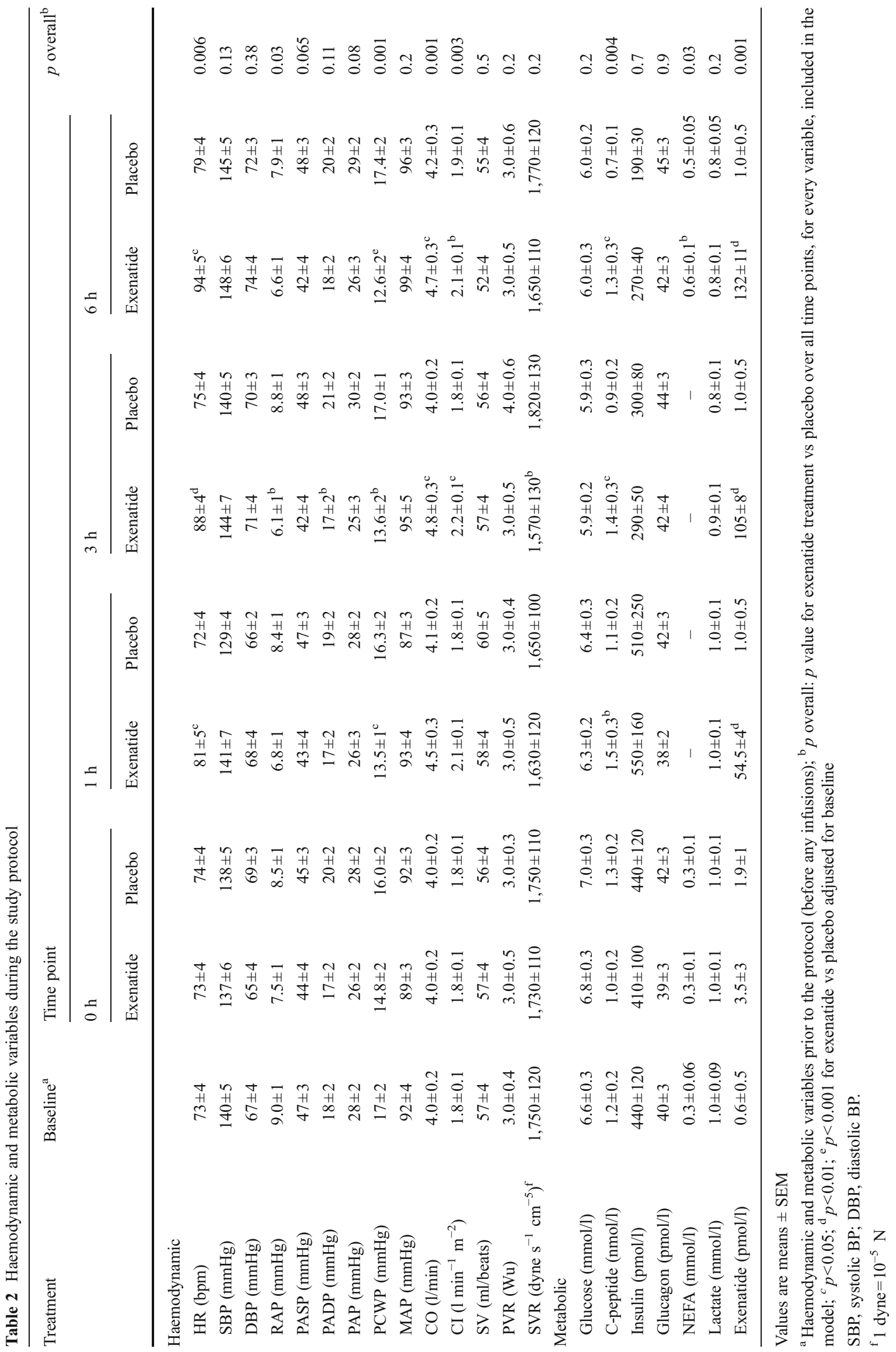


Fig. 2 Relative changes of (a) $\mathrm{CI}$ and (b) PCWP from baseline and during 1,3 and $6 \mathrm{~h}$ infusions of exenatide vs placebo. Dotted lines visualise the calculated endpoint levels i.e. an increase by $20 \%$ for CI or a decrease by $20 \%$ for PCWP, respectively. For the proportions of patients that reached the endpoint of CI and/or PCWP, see text. a $1 \mathrm{~h}$, $p=0.03 ; 3 \mathrm{~h}, p=0.001 ; 6 \mathrm{~h}$, $p=0.002$, exenatide vs placebo. b $1 \mathrm{~h}, p=0.08 ; 3 \mathrm{~h}, p=0.03 ; 6 \mathrm{~h}$, $p=0.002$, exenatide vs placebo
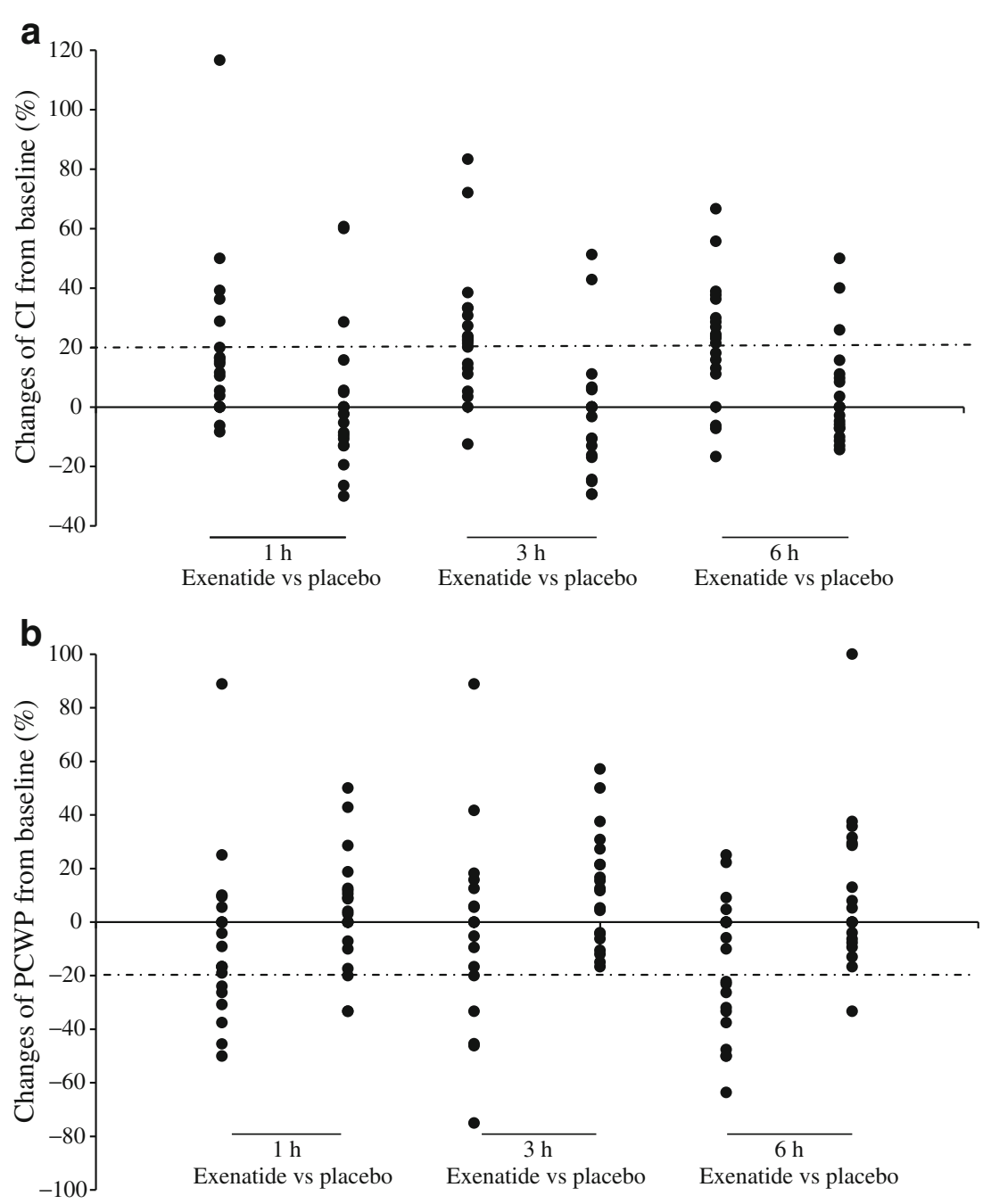

blood pressure (from $175 / 85$ to $195 / 105 \mathrm{mmHg}$ ) that required $1 \mathrm{~h}$ of i.v. nitroglycerine after the exenatide infusion. All analyses of the outcomes were performed both with and without these three patients. As the results for primary and secondary endpoints were almost identical in the intention to treat and the per protocol populations, we have chosen to present the data from the intention to treat population.

\section{Discussion}

We demonstrate that exenatide exerts rapid haemodynamic effects in male type 2 diabetic patients with CHF. Previous studies show that short-term infusion of GLP-1 improves LV heart failure in patients with acute MI [3], as does chronic infusion in patients with CHF [4]. In a recent randomised, double-blind, crossover-designed study, $48 \mathrm{~h}$ infusion of GLP-1 in patients without diabetes with compensated heart failure had no significant effects on CI or heart filling pressures, although a small but significant increase in HR and diastolic blood pressure was observed [5]. These findings are similar to the present study; however, the settings of the studies differ in terms of drugs, methods, patients and conditions, and therefore are not easily comparable.

The increase in CI was contingent upon an increase in HR without any change in SV, indicative of a positive chronotropic effect of exenatide. This is in contrast to rodent studies, in which exenatide dose-dependently induced chronotropic effects paralleled by pressor action [14]. The GLP1 receptor is abundantly expressed in areas in the brain known to be involved in the regulation of cardiovascular function [15], in blood vessels $[8,16]$ and in the heart $[8$, 17]. In mice, stimulation of central GLP-1 receptors by exenatide modulates parasympathetic outflow, thereby increasing HR [18, 19]. In contrast, GLP-1 increases sympathetic vasoconstrictor neural activity but does not appear to affect cardiac sympathetic or parasympathetic activity in healthy humans [20]. Acute injection of exenatide reportedly increases HR in humans [21], although chronic exenatide treatment produced no clinically meaningful effects on HR 
in type 2 diabetic patients [22]. The findings undoubtedly raise questions about the efficacy and safety of exenatide treatment in patients with type 2 diabetes and CHF. Chronically raised HR is a risk factor for adverse outcome in patients with $\mathrm{CHF}$, and drugs lowering HR improve clinical outcome in CHF. Although exenatide treatment was associated with a lower risk of cardiovascular disease (CVD) than other glucose-lowering treatments in a large retrospective LifeLink database [23], there is no robust evidence that treatment with exenatide affects the CVD outcome.

Exenatide significantly decreased PCWP and RAP, but changes in these variables were small compared with other studies [13]. Patients with type 2 diabetes might suffer from heart failure despite having a normal ejection fraction. These patients usually have diastolic dysfunction, suggested to be due to fibrosis [24], or to the inability of the myocardium to switch from fat to carbohydrate as fuel for oxidative energy production [25]. Our study design cannot discriminate between any of these mechanisms. GLP-1 ameliorates cardiac dysfunction in canine [2] and rodent [26, 27] models of heart failure by increasing myocardial glucose use, recently also demonstrated by chronic exenatide treatment in a murine model with dilated cardiomyopathy [9]. Although we carefully matched the metabolic state between treatments, we also cannot rule out the possibility that exenatide might have shifted myocardial substrate metabolism towards a more energetically favourable substrate, improving myocardial performance. Moreover, exenatide might have induced diuresis, explaining the decreased RAP seen in present study, recently shown for GLP-1 that induces diuresis in rats [28] and humans [29] mediated by changes in renal haemodynamics. However, the lack of positive inotropic action of exenatide is consistent with in vitro findings, in which GLP-1 failed to enhance contractility in cardiomyocytes [30]. Even with a fixed low SV, the increase in HR and the improvement of CI noted in the current study might have reduced the diastolic filling pressure. Interestingly, short term infusion of GLP-1 improves ischaemic LV systolic and diastolic dysfunction, mitigating LV stunning in patients awaiting elective percutaneous coronary intervention [7]. In that study, a second cardiac catheter was placed in the LV, which monitored contractile performance in this ventricle. In our study, such information on the pressure-volume loops was regrettably unavailable, but might have given some insight as to why participants with CAD or nonCAD respond differently to exenatide in terms of CI increase. However, it is important to remember that the present study was un-powered for such subgroup analyses. Nevertheless, acute infusion of exenatide seems to be valuable in protecting the ischaemic myocardium [31]. Furthermore, we also cannot entirely exclude the possibility that exenatide might have induced some vasodilatation in the vessel beds, thereby decreasing PCWP and RAP. Exenatide reportedly induces vasodilatation in hind quarters in rodents as a result of activation of $\beta$-adrenergic receptors [32]. In the current study, 19 out of 20 participants were on chronic $\beta$-blocker treatment, which might have masked a further vasodilatation action by exenatide. A vasodilatory effect is also compatible with the recent finding that exenatide upregulates endothelial nitric oxide synthase (eNOS), promoting release of nitric oxide from human coronary artery endothelial cells [33]. In contrast, exenatide does not directly act as a vasodilator in preconstricted rat conduit artery rings $[8$, 34]. A dual control of the cardiovascular effects of exenatide has been proposed via the central and peripheral nervous systems, suggested to involve both the autonomic and nonautonomic nervous systems [35]. This might explain some of the discrepant findings in this study.

It has been suggested that CHF associates with a hyperadrenergic state that increases circulating NEFA levels [36]. In type 2 diabetic patients, levels of circulating NEFAs often exceed the normal range, reflecting lipotoxicity and insulin resistance. Lipotoxicity appears to be more important in women, who seem more susceptible to the adverse myocardial metabolic effects of NEFAs compared with men [37]. Despite considerable efforts to include women in this study, all available female participants declined to enter into the study. Sex differences in myocardial metabolism have been suggested inasmuch as sex may modulate the response of therapeutic strategies in heart failure and type 2 diabetes [37]. In the current study, NEFAs increased during both protocols, probably reflecting catabolism during fasting. Interestingly, exenatide increased NEFA levels even further without any changes in plasma lactate levels. There were no differences in glucose, insulin or glucagon levels. C-peptide levels were higher during exenatide infusion, with somewhat less need for insulin, reflecting the known insulinotropic action by exenatide. Without any metabolic changes during the exenatide infusion, the elevated NEFA levels were probably due to the increased HR, reflecting a hyperadrenergic state. This was mirrored by a tendency of increased MAP in both groups, which might have been elicited by $\beta$-adrenoreceptor activation [32]. Thus, we cannot exclude the possibility that the tachycardia, concomitant with elevated NEFA levels, evoked by exenatide might be detrimental for a failing heart. Two patients required digoxin in order to terminate a highfrequency AF and a third patient needed temporary nitroglycerine infusion because of increased blood pressure during the exenatide infusion. Furthermore, another six patients suffered from nausea and vomiting. Despite these adverse events, no symptoms of deteriorated heart failure or other serious adverse events were observed in any patient during the protocol.

Strengths and limitations The strengths of our study include the fact that this was a double-blind, placebo-controlled, crossover study. The invasive pulmonary artery catheter 
method remains the gold standard for monitoring cardiac filling pressure. There are also limitations of the study. The findings are confined to male patients admitted to the hospital for CHF with type 2 diabetes and therefore it cannot be inferred that such haemodynamic effects will occur in a mixed-sex population. Not using echocardiographic monitoring precluded us from investigating the effects of exenatide on contractility and diastolic function that would have revealed any harmful effects to the heart.

In conclusion, the present study shows that exenatide caused a significant improvement of $\mathrm{CI}$, contingent upon a marked increase in HR, in type 2 diabetic patients with CHF. These effects occurred together with a decrease in PCWP and RAP, and with reasonable tolerability of the drug. Studies of the clinical implications of the use of exenatide in patients with CHF are still in their infancy and further prospective studies with clinically hard endpoints, such as cardiovascular morbidity and mortality, are very much needed.

Acknowledgements We thank H. Pettersson and L. Benson (Department of Clinical Science and Education, Karolinska Institutet, Sweden) for excellent statistical advice.

Funding Financial support was provided through the regional agreement on medical training and clinical research (ALF) between Stockholm County Council and the Karolinska Institute, and by the Swedish Society for Medical Research, the Swedish Society of Medicine, Stiftelsen Serafimerlasarettet, the Swedish Heart and Lung foundation, Eli Lilly Amylin Alliance, the European Foundation for the Study of Diabetes, Karolinska Institutet Foundations, and Stiftelsen Olle Engkvist Byggmästare. None of the funding sources had any involvement in the study design; collection, analysis, or interpretation of data; the writing of the report; or the decision to submit the paper.

Duality of interest D. Nathanson has received consultancy fees from Merck. T. Nyström has received consultancy fees from Eli Lilly, Novo Nordisk, Merck and sanofi-aventis. Å. Sjöholm has received research grants, consultancy fees, lecture honoraria and fees for expert testimony from Eli Lilly, Novo Nordisk, Merck, Boehringer-Ingelheim, AstraZeneca, Novartis and sanofi-aventis and is on the national/Nordic/European/global advisory boards of Eli Lilly, Merck, Boehringer-Ingelheim, AstraZeneca, sanofi-aventis and Novartis.

Contribution statement All authors contributed to the study conception and design. MF and BU conducted the heart catheterisations. $\mathrm{DN}, \mathrm{BU}$ and TN analysed data. DN and TN wrote the first draft of the paper. All authors commented on and took part in the revision of the paper and approved the final version.

\section{References}

1. Nyström T (2008) The potential beneficial role of glucagon-like peptide-1 in endothelial dysfunction and heart failure associated with insulin resistance. Hormon Metab Res 40:593-606

2. Nikolaidis LA, Elahi D, Hentosz T et al (2004) Recombinant glucagon-like peptide-1 increases myocardial glucose uptake and improves left ventricular performance in conscious dogs with pacing-induced dilated cardiomyopathy. Circulation 110:955-961

3. Nikolaidis LA, Mankad S, Sokos GG et al (2004) Effects of glucagon-like peptide-1 in patients with acute myocardial infarction and left ventricular dysfunction after successful reperfusion. Circulation 109:962-965

4. Sokos GG, Nikolaidis LA, Mankad S, Elahi D, Shannon RP (2006) Glucagon-like peptide-1 infusion improves left ventricular ejection fraction and functional status in patients with chronic heart failure. J Card Fail 12:694-699

5. Halbirk M, Norrelund H, Møller N et al (2010) Cardiovascular and metabolic effects of 48-h glucagon-like peptide-1 infusion in compensated chronic patients with heart failure. Am J Physiol 298: H1096-H1102

6. Sokos GG, Bolukoglu H, German J et al (2007) Effect of glucagon-like peptide-1 (GLP-1) on glycemic control and left ventricular function in patients undergoing coronary artery bypass grafting. Am J Cardiol 100:824-829

7. Read PA, Hoole SP, White PA et al (2011) A pilot study to assess whether glucagon-like peptide-1 protects the heart from ischemic dysfunction and attenuates stunning after coronary balloon occlusion in humans. Circ Cardiovasc Interv 4:266-272

8. Ban K, Noyan-Ashraf MH, Hoefer J, Bolz SS, Drucker DJ, Husain M (2008) Cardioprotective and vasodilatory actions of glucagonlike peptide 1 receptor are mediated through both glucagon-like peptide 1 receptor-dependent and -independent pathways. Circulation 117:2340-2350

9. Vyas AK, Yang KC, Woo D et al (2011) Exenatide improves glucose homeostasis and prolongs survival in a murine model of dilated cardiomyopathy. PLoS One 6:e17178

10. Liu Q, Anderson C, Broyde A et al (2010) Glucagon-like peptide-1 and the exenatide analogue AC3174 improve cardiac function, cardiac remodeling, and survival in rats with chronic heart failure. Cardiovasc Diabetol 9:76

11. Edwards CM, Stanley SA, Davis R et al (2001) Exendin-4 reduces fasting and postprandial glucose and decreases energy intake in healthy volunteers. Am J Physiol 281:E155-E161

12. Sonne DP, Engstrøm T, Treiman M (2008) Protective effects of GLP-1 analogues exendin-4 and GLP-1(9-36) amide against ischemia-reperfusion injury in rat heart. Regul Pept 146:243-249

13. Slawsky MT, Colucci WS, Gottlieb SS et al (2000) Acute hemodynamic and clinical effects of levosimendan in patients with severe heart failure. Study Investigators. Circulation 102:2222-2227

14. Barragan JM, Rodriguez RE, Eng J, Blazquez E (1996) Interactions of exendin-(9-39) with the effects of glucagon-like peptide-1(7-36) amide and of exendin-4 on arterial blood pressure and heart rate in rats. Regul Pept 67:63-68

15. Yamamoto H, Lee CE, Marcus JN et al (2002) Glucagon-like peptide-1 receptor stimulation increases blood pressure and heart rate and activates autonomic regulatory neurons. J Clin Investig 110:43-52

16. Nyström T, Gutniak MK, Zhang Q et al (2004) Effects of glucagon-like peptide-1 on endothelial function in type 2 diabetes patients with stable coronary artery disease. Am J Physiol 287: E1209-E1215

17. Gros R, You X, Baggio LL et al (2003) Cardiac function in mice lacking the glucagon-like peptide-1 receptor. Endocrinology $144: 2242-2252$

18. Griffioen KJ, Wan R, Okun E et al (2010) GLP-1 receptor stimulation depresses heart rate variability and inhibits neurotransmission to cardiac vagal neurons. Cardiovasc Res 89:72-78

19. Cabou C, Campistron G, Marsollier N et al (2008) Brain glucagonlike peptide-1 regulates arterial blood flow, heart rate, and insulin sensitivity. Diabetes 57:2577-2587

20. Bharucha AE, Charkoudian N, Andrews CN et al (2008) Effects of glucagon-like peptide-1, yohimbine, and nitrergic modulation on 
sympathetic and parasympathetic activity in humans. Am J Physiol 295:R874-R880

21. Kothare PA, Linnebjerg H, Isaka Y et al (2008) Pharmacokinetics, pharmacodynamics, tolerability, and safety of exenatide in Japanese patients with type 2 diabetes mellitus. J Clin Pharmacol 48:1389-1399

22. Gill A, Hoogwerf BJ, Burger J et al (2010) Effect of exenatide on heart rate and blood pressure in subjects with type 2 diabetes mellitus: a double-blind, placebo-controlled, randomized pilot study. Cardiovasc Diabetol 9:6

23. Best JH, Hoogwerf BJ, Herman WH et al (2010) Risk of cardiovascular disease events in patients with type 2 diabetes prescribed the glucagon-like peptide 1 (GLP-1) receptor agonist exenatide twice daily or other glucose-lowering therapies: a retrospective analysis of the LifeLink database. Diabetes Care 34:90-95

24. van Heerebeek L, Hamdani N, Handoko ML et al (2008) Diastolic stiffness of the failing diabetic heart: importance of fibrosis, advanced glycation end products, and myocyte resting tension. Circulation 117:43-51

25. Taegtmeyer H (2004) Cardiac metabolism as a target for the treatment of heart failure. Circulation 110:894-896

26. Bhashyam S, Fields AV, Patterson B et al (2010) Glucagon-like peptide-1 increases myocardial glucose uptake via p38alpha MAP kinase-mediated, nitric oxide-dependent mechanisms in conscious dogs with dilated cardiomyopathy. Circulation 3:512-521

27. Poornima I, Brown SB, Bhashyam S, Parikh P, Bolukoglu H, Shannon RP (2008) Chronic glucagon-like peptide-1 infusion sustains left ventricular systolic function and prolongs survival in the spontaneously hypertensive, heart failure-prone rat. Circulation $1: 153-160$

28. Crajoinas RO, Oricchio FT, Pessoa TD et al (2011) Mechanisms mediating the diuretic and natriuretic actions of the incretin hormone glucagon-like peptide-1. Am J Physiol Renal Physiol 301:F355-F363

29. Gutzwiller JP, Tschopp S, Bock A et al (2004) Glucagon-like peptide 1 induces natriuresis in healthy subjects and in insulinresistant obese men. J Clin Endocrinol Metab 89:3055-3061

30. Vila Petroff MG, Egan JM, Wang X, Sollott SJ (2001) Glucagonlike peptide-1 increases cAMP but fails to augment contraction in adult rat cardiac myocytes. Circ Res 89:445-452

31. Lønborg J, Vejlstrup N, Kelbaek H, et al. (2011) Exenatide reduces reperfusion injury in patients with ST-segment elevation myocardial infarction. Eur H J doi:10.1093/eurheartj/ehr309 [Epub ahead of print]

32. Gardiner SM, March JE, Kemp PA, Bennett T (2006) Mesenteric vasoconstriction and hindquarters vasodilatation accompany the pressor actions of exendin-4 in conscious rats. J Pharmacol Exp Ther 316:852-859

33. Erdogdu O, Nathanson D, Sjöholm A, Nyström T, Zhang Q (2010) Exendin-4 stimulates proliferation of human coronary artery endothelial cells through eNOS-, PKA- and PI3K/Akt-dependent pathways and requires GLP-1 receptor. Mol Cell Endocrinol 325:26-35

34. Nathanson D, Erdogdu O, Pernow J, Zhang Q, Nyström T (2009) Endothelial dysfunction induced by triglycerides is not restored by exenatide in rat conduit arteries ex vivo. Regul Pept 157:8-13

35. Gardiner SM, March JE, Kemp PA, Bennett T (2008) Autonomic nervous system-dependent and -independent cardiovascular effects of exendin-4 infusion in conscious rats. Br J Pharmacol 154:60-71

36. Opie LH, Knuuti J (2009) The adrenergic-fatty acid load in heart failure. J Am Coll Cardiol 54:1637-1646

37. Peterson LR, Saeed IM, McGill JB et al (2011) Sex and type 2 diabetes: obesity-independent effects on left ventricular substrate metabolism and relaxation in humans. Obesity (Silver Spring). doi:10.1038/oby.2011.208 